\title{
A DIVINA COMÉDIA REVISITADA: OS PERCURSOS REFLEXIVOS DE GIORGIO AGAMBEN NOS VERSOS DANTESCOS
}

\author{
Monique Bione Silva ${ }^{*}$ \\ Universidade Federal de Santa Catarina
}

Resumo: Este artigo busca estudar alguns pontos da Divina Comédia e do seu autor através da perspectiva do filósofo e crítico literário italiano Giorgio Agamben e, também, como ele cria rizomas entre os seus textos utilizando como objeto de estudo o poeta florentino. Sendo um dos poemas mais estudados em distintas áreas acadêmicas, os cantos dantescos perpassam o tempo e permanecem atuais e atuantes, não apenas em releituras de produções poéticas, mas também no olhar de estudiosos como Agamben. O crítico literário apresenta um compilado de vários textos, num estudo diferenciado da poesia dantesca, em livros como Estâncias e Categorie Italiane. Agamben aborda a questão da significação da poesia e como esta pode ser decisiva para a construção poética, assim como a conceituação do enjambement; repensa o título da Comédia; traz o entendimento sobre a contemporaneidade dos poetas, principalmente Dante; e mergulha nos fundamentos teológicos da política para pensar sobre a questão da aclamação como centro dos dispositivos políticos.

Palavras-chave: Dante Alighieri. A Divina Comédia. Giorgio Agamben. Literatura. Política.

\author{
A valia do homem está \\ na capacidade de transformar \\ a sina em trova. \\ Morte em vida. \\ De tirar água de cacto, \\ comida de lagarto \\ e, mesmo assim, agradecer \\ a cada vez que os cílios \\ se desgrudam, \\ buscando uma inédita lucidez. \\ Buscando a luz mais uma (última) vez.
}

\section{Esta obra está licenciada sob uma Creative Commons - Atribuição 4.0}

\footnotetext{
* Possui graduação em Jornalismo pelo IELUSC e mestrado em Teoria Literária pela Universidade Federal de Santa Catarina. Sua dissertação de mestrado tem como tema principal a sombra da poesia melancólica dantesca em alguns versos de Carlos Drummond de Andrade e Eugenio Montale. É graduanda em Letras - Língua Portuguesa e Respectivas Literaturas, jornalista, editora e revisora da revista Caminho Aberto do Instituto Federal de Educação Ciência e Tecnologia de Santa Catarina. Tem experiência na área de Comunicação, Educação e EaD. E-mail: nickbione@gmail.com
} 


\section{Introdução}

Não poderíamos começar a narrar as viagens do filósofo e crítico literário Giorgio Agamben sem antes contarmos a mais importante e inimaginável de todas: a viagem do poeta do medievo Dante Alighieri. Poeta é um adjetivo demasiado simples para nomear tal homem que, mesmo com todas as biografias existentes, ainda não foi suficientemente descrito, com total inteireza de vida, e os feitos desse autor singular. Tais biografias apenas nos dão a certeza de que muito já foi falado, porém, ainda existe muito a se estudar.

Dante Alighieri teria nascido em maio de 1265, na hoje conhecida região da Toscana. A cidade, na época de Dante, era chamada de Florença que, por sua vez, significa "florida" ou "florescente". Era de família relativamente nobre, apesar de não ser das mais ricas e sem muito prestígio diante dos demais nobres. A mãe do poeta faleceu quando ele tinha apenas dois anos, sendo a primeira de muitas marcas de perdas que comporiam a sua vida. Tornou-se um homem muito culto e com uma incrível capacidade de domínio sobre a erudição.

Segundo alguns biógrafos, foi ainda criança que Dante conheceu Beatriz Portinari, e, mesmo nunca tendo um relacionamento amoroso com a mesma, ela marcaria a sua vida para sempre. O sentimento do florentino por Beatriz o influenciaria de modo tal que, provavelmente, se tivesse existido um relacionamento concreto, isso jamais aconteceria. Este encontro estaria narrado em sua primeira obra, Vida Nova: “Girando sobre si, já luminoso céu tinha voltado nove vezes ao mesmo ponto, quando vi pela primeira vez a gloriosa dama de meus pensamentos a quem muitos chamavam de Beatriz" (ALIGHIERI, 1993, p. 7). Sempre citada como ser angelical, Dante exalava a mais pura admiração por aquela que seria exemplo de beatitude e pureza.

Ao escrever a Divina Comédia, Dante criou uma das obras poéticas mais complexas e admiradas. Com uma composição de 14.233 decassílabos, em um grupo de três versos, que representam a Trindade, se encontra uma infinidade de significados e história. O poeta inseriu naquelas linhas toda a sua indagação sobre a angústia da vida humana e, ao escolher uma nova língua, compartilhou essas aflições com o povo. Esse mesmo povo que, excluído do clero, se conformava com a escuridão do não saber. De acordo com o pensamento dantesco, o desconhecido não salva, pois não é possível se redimir dos pecados sem o conhecimento dos mesmos.

Foi com uma 'nova' língua, o vulgar italiano, que Dante apresentou os cenários angustiantes e tenebrosos do Inferno, do Purgatório e as imagens angelicais do Paraíso que, juntos, marcam os cem cantos da obra. O poeta compôs a primeira parte da Commedia, o 
Inferno, por volta de 1308, o Purgatório em 1313 e o Paraíso em 1321, sendo que este último não chegou a concluir, morreu antes. Tal fato fez com que, muitos anos depois, muito se questionasse sobre quem escreveu o final do Paraíso, sendo a autoria do filho de Dante a mais conhecida e afirmada. Entre vários autores que estudaram e citaram a Divina Comédia, podemos mencionar o escritor e tradutor mexicano Octavio Paz (1993, p. 14), para falar sobre as características que marcam a maior obra escrita pelo poeta florentino.

\begin{abstract}
A Divina Comédia é um poema no qual reúnem todos os gêneros anteriores épicos, míticos, filosóficos - e no qual se conta uma história. O tema do poema não é o regresso de Ulisses a Ítaca ou as aventuras de Enéias: relata a história da viagem de um homem ao outro mundo. Esse homem não é um herói, como Gilgamesh, e sim um pecador - e mais: esse pecador é o próprio poeta, o florentino Dante. O poema antigo era impessoal; com Dante aparece o eu.
\end{abstract}

Sendo um homem ativo na sociedade da Alta Idade Média, vivenciou toda a essência cultural, religiosa e política de sua época. Estudioso, e com uma aguçada sagacidade pelo saber, Dante compilou várias ideias a respeito do seu meio, tanto presente como futuro, isto é, a sua forma de encarar o mundo permitiu escrever a Divina Comédia sob uma nova ótica, destacando a relação homem/Deus, homem/homem e homem/si mesmo. Tal atitude era vista com total estranhamento pelos de sua época, já que o mesmo vivia diante do teocentrismo.

Com a ênfase no eu, Dante traz outra grande mudança para a literatura da época, ele se transforma no protagonista da própria história e isto só foi possível pelo fato do poema se tratar de um poema alegórico. É surpreendente a narração de uma viagem fictícia e que, ao mesmo passo, tornou-se tão real que para muitos eram considerados relatos verídicos e prenúncios de um futuro verdadeiro, "a viagem interior do herói ao país dos imortais, por mais fantástica que possa parecer, se apresenta como um fato real, absolutamente real" (PAZ, 1993, p. 15).

Voltando a falar sobre Beatriz, mesmo após a sua morte, Dante continuou a usando como temática para as suas obras, evocando o espírito de amor e salvação na sua imagem. O filósofo e crítico literário Giorgio Agamben dedica um capítulo de Estâncias, intitulado "Espírito de amor", ao tema constante na obra poética dantesca. Agamben diz que Klein bem observou, no soneto "Oltre la spera che piú larga gira", contida no final de Vida Nova, que Dante fez um prenúncio da sua viagem na Divina Comédia. Ele se vê em espírito, pois se mostra com a possibilidade de separar-se do corpo físico para receber a sua visão. Esse seria o "espírito fantástico" sobre o qual comenta Agamben. Tal concepção é citada por Dante, no canto XVII do Purgatório, na invocação à "imaginativa", nesta, ele indaga o que move a fantasia, e diz que, uma vez arrebatada, na sua visão, não poderia ser movida pelo sentido. 
Este tema sobre o espírito ainda acompanha Dante no Convívio, quando ele diz que o espírito vem pelos raios da estrela (AGAMBEN, 2012).

Nos seus três últimos anos de vida, Dante ficou em Ravena, e foi lá que escreveu as "últimas" linhas da Divina Comédia. Contraiu malária e morreu em 14 de setembro de 1321. Foi enterrado no mesmo lugar, sendo que, anos depois, Florença solicitou seus restos mortais. Tal pedido foi aceito, porém, descobriu-se que o caixão em que, supostamente estariam seus restos mortais, estava vazio.

Seja impulsionado pelo amor por Beatriz ou por sua crença e indagações sobre a vida, o poeta/profeta, tornou-se um homem notório na sua época e além dela. Foi ambicioso na produção literária e queria dar a palavra ao povo, que a desconhecia. Almejava abranger toda a experiência da vida, nas suas múltiplas dimensões. Para o amigo Canfrancesco della Scala, conhecido como Cangrande, o poeta escreveu que o objetivo do seu poema é o de que todos, ao terem contato com o mesmo, tivessem a possibilidade de abandonar o estado de sofrimento e serem transportados para a felicidade. Dante ambicionava que a sua obra fosse entendida como um meio para se elevar o estado de consciência individual com o simples ato de lê-la.

Ambiciosa afirmação de Dante em relação à própria poesia pode suscitar maiores reflexões sobre a significação da poesia para a sociedade. E é com observações sobre a obra poética dantesca que Giorgio Agamben aborda o tema e incita ao entendimento da tese do enjambement e a sua inserção na composição do poema, inclusive de Dante.

\section{O instituto poético - a busca do enjambement no poema}

Ao termos uma ideia sobre a relevância que uma obra como a Divina Comédia tem frente a sociedade, nesse momento, nos perguntamos: por que pensar a poesia? A reflexão sobre o seu papel no contexto social e a perspectiva através dos olhos do leitor podem ser percebidos nos versos dantescos, segundo nossa análise.

\footnotetext{
Por que nos importa a poesia? A maneira em que se configuram as respostas confere a esta pergunta a medida da absoluta não trivialidade da interrogação. Isso porque o âmbito dos respondedores se reparte exatamente entre os que afirmam a importância da poesia apenas a pacto de confundi-la inteiramente com a vida e aqueles para os quais sua importância é função exclusiva de seu isolamento da vida. Ambas as vertentes desmentem, assim, seu intento aparente: a primeira porque sacrifica a poesia à vida em que a resolve, e a segunda porque sanciona, em última análise, sua impotência diante da vida. (AGAMBEN apud BERNARDINI, 2011, p. 31-32) ${ }^{1}$
}

\footnotetext{
${ }^{1}$ Texto contido em A coisa perdida - Agamben comenta Caproni, 2011. Publicado originalmente em Giorgio Caproni - Tutte le poesie. Milão: Garzanti, 1999.
}

Anu. Lit., Florianópolis, v. 22, n. 2, p. 38-52, 2017. ISSNe 2175-7917 
Diante e contra tais oposições, está a experiência do poeta, pois se a vida e a poesia são divergentes em alguns momentos, também podem se confundir na sua dessubjetivização que, por sua vez, é a perda de si, necessária para a criação da palavra. Vivência, filosofia ou ficção, inseridas na composição dos poemas, são questões que voltaremos a abordar mais adiante. Antes, buscaremos conceituar a estrutura do poema através de Agamben.

Definir um sentimento, uma sensação ou, simplesmente, uma história confusa. Ao se escrever poesia, geralmente, quem a cria tenta encontrar uma definição para si e para a vida de certa maneira, busca uma singela clareza para pensamentos e teorias. Por vezes o poeta nada busca ou deseja, apenas expele algo que o apaixona ou enlouquece e que o impele a seguir ou parar, teorizar. E é pensando no poema e na angústia, que perpassa a produção do mesmo, que se pode pensar sobre a teoria de "O fim do poema", de Agamben, um dos capítulos de Categorias italianas, onde se encontra o sentido do mesmo. No citado capítulo, o autor parte para a questão do poema e apresenta a tese do enjambement presente, inclusive, em Dante, a respeito do fim do poema:

\footnotetext{
Como se o poema, enquanto estrutura formal, não pudesse, não devesse findar, como se a possibilidade do fim lhe fosse radicalmente subtraída, já que implicaria esse impossível poético que é a coincidência exata de som e sentido. No ponto em que o som está prestes a arruinar-se no abismo do sentido, o poema procura uma saída suspendendo, por assim dizer, o próprio fim, numa declaração de estado de emergência poética. (AGAMBEN, 2014, p. 183-184)
}

Ainda sobre o referido capítulo, Agamben busca definir um instituto poético que, para ele, está até então esquecido ou não lhe é dado o devido valor. Para fazer a análise do citado tema, o teórico expõe a composição do poema - ele é o contraste e a oposição entre som e sentido, entre semiótica e semântica. Tal definição é de extrema importância para todo o estudo de Agamben, bem como para se chegar à sua tese do enjambement. Para o filósofo, "a possibilidade do enjambement constitui o único critério que permite distinguir a poesia da prosa. Pois o que é o enjambement senão a oposição entre um limite métrico e um limite sintático, uma pausa prosódica e uma pausa semântica?” (AGAMBEN, 2014, p. 178). Ou seja, para ele, só se poderia definir como poético aquilo em que essa oposição é aplicada ou possível. Tal conceito é bem valorizado pelos poetas medievais, inclusive Dante Alighieri.

Segundo Agamben (2014, p. 180), Dante se mostrou totalmente consciente de que poesia "é um organismo fundado sobre a percepção de limites e terminações que definem, sem jamais coincidir completamente, e quase em alternada disputa, unidades sonoras (ou gráficas) e unidades semânticas". Podemos observar essa característica em De vulgari eloquentia, onde o poeta faz a oposição entre "o canto (cantio), como unidade de sentido 
(sententia), às estâncias (stantiae), como unidades puramente métricas" (AGAMBEN, 2014, p. 180). Agamben examina um trecho da supracitada obra e diz que Dante coloca, mesmo que de maneira implícita, o problema do fim da poesia:

A passagem se encontra no livro III (XII, 7-8), em que o poeta trata da disposição das rimas na canção. Após ter definido a rima irrelata (que alguém sugeriu denominar clavis), o texto diz: Pulcerrime tamen se habent ultimorium carminum desinentiae, si cum ritmo in silentium cadunt. (Belíssimas são as terminações dos últimos versos, se caem, com as rimas, no silêncio). O que é essa queda do poema no silêncio? O que é uma beleza que cai? E o que resta do poema depois da sua ruína? (AGAMBEN, 2014, p. 184)

O enjambement nem sempre tem clareza e não pode estar inserido no final da poesia, no último verso. Isso porque tal parte deve ser bem estruturada no seu sentido, por mais que toda a poesia seja confusa. Ainda segundo Agamben, a "mensagem" do poema está nas suas pausas, nas suas obscuras isenções de sentidos e na sua quietude. É através do abismo, inserido no poema, que se pode chegar a algum lugar, mesmo que indefinido. A beleza dos versos está na suspensão do inacabado. É essa suspensão que podemos encontrar na Divina Comédia.

A mensagem suspensa de Dante pode ser lida com uma filosofia eterna justamente por tal característica. Ela pode ser interpretada de diversas formas, contextos e sentidos, assim como uma poesia deveria ser. São as possibilidades que fazem da poesia algo essencial e único.

Agamben fala sobre a essência do poema italiano em um capítulo de A coisa perdida: Agamben comenta Caproni, onde diz que "Nas origens da poesia italiana, essa unidade do vivido e do poetado, no medium da língua, num ponto singular, mas sem sujeito, foi enunciada como tarefa própria do poeta, na terzina em que Dante define o Stilnovo:" (2011, p. 32) e exemplifica com o seguinte trecho: "E eu a ele: 'Eu sou um que, quando / Amor me (in)spira, noto, e daquele modo / que ele me dita vou significando" (AGAMBEN, 2011, p. 32).

Agamben diz que, aqui, o poeta é, desde o seu início, dessubjetivizado com o genérico um, faz a junção entre o vivido e o poetado. A poesia se torna viva porque a vida e a poesia do poeta se compõem ou se confundem: “A língua é a mediação. Poeta é quem, na palavra, gera a vida. A vida, que o poeta gera na palavra, é subtraída tanto da vivência do indivíduo psicossomático quanto da indivisibilidade biológica do gênero". (AGAMBEN, 2011, p. 32).

Os diversos sentidos do poema podem ser buscados a cada linha, a cada som, a cada 
possível significação, com toda a possibilidade que pode ser atribuída ao contexto temporal, pessoal, cultural e histórico. Uma vez abordada a importância da busca pelo significado mais amplo de um poema, Agamben traz à tona, em outra obra, reflexões sobre a escolha do título Commedia por Dante. Por quais caminhos podemos seguir para a interpretação mais plausível do mesmo?

\section{Reflexões acerca do título Comédia}

Categorias italianas é o conjunto de oito estudos que, inicialmente, seria um projeto para uma revista da editora Einaudi em parceria com Ítalo Calvino e Claudio Rugafiori, entre 1974 e 1976. Tinha como objetivo estudar as categorias da cultura italiana, visando abranger suas características fundamentais, em particular, a literária. Tal projeto acabou não dando certo e transformou-se em um livro, tendo o primeiro capítulo a abordagem da oposição tragédia/comédia e, como objeto, a Divina Comédia, de Dante Alighieri.

No capítulo intitulado justamente Comédia, Giorgio Agamben fala sobre os motivos para tal título da obra dantesca e porque foi desdenhado pela crítica, sendo que, pela sua ótica, ainda merece estudos mais assíduos: "Num certo sentido, no que diz respeito à inteligência dos motivos da escolha cômica de Dante, a crítica moderna não foi muito além das observações de Benvenuto da Imola, ou daquelas de Boccaccio" (AGAMBEN, 2014, p.17).

Agamben tem profunda afinidade e domínio com os temas literários e é um grande estudioso de autores e críticos. Talvez seja esse o motivo dele adentrar o problema de aparente contradição do título dantesco diante das demais produções do poeta. "O fato de as razões da titulação cômica parecerem, para os mais antigos comentadores, problemáticas e incoerentes já poucos anos após a morte do autor, testemunha o quão secretamente esteja, nessa mudança, guardando um nó histórico” (AGAMBEN, 2014, p. 15-16).

Atualmente, comédia, no seu conceito mais raso, é o termo que se emprega para classificar algo, cênico ou não, que é engraçado, humorístico. Devemos pensar essa categoria nos transportando para a época medieval, onde Dante escolheu o título Comédia dando-lhe um conceito muito bem fundamentado. Agamben (2014, p. 18) diz que "O fato de a titulação cômica parecer discordante em relação a tudo quanto nós conhecemos de suas ideias, e daquelas de seu tempo, deve, pelo contrário, levar-nos a presumir que ela tenha sido atentamente meditada". A opção por este tema teve um significado profundo, uma demonstração de ruptura com o estilo do próprio poeta. Ele refere-se à comédia como algo que é comum, acessível. O povo não tinha a oportunidade de acesso, de entendimento da bíblia, uma vez que as missas eram conduzidas/ faladas em latim. Mas, é importante deixar 
claro que a escolha do poeta não tem relação com uma escolha linguística, latim ou vulgar, e sim, com o tema a que essa se refere.

Agamben aprofunda a reflexão sobre a preferência de Dante com o referido tema ao analisar sobre a carta do mesmo à Cangrande e traz uma questão: será que deveríamos levar o título a sério? Agamben diz que a escolha do título Comédia se deve à perdição e à salvação, pois as tragédias têm a característica de ter o início próspero e o fim trágico, já a comédia é justamente o contrário, o início é difícil e o fim próspero. A Divina Comédia é uma ilustração do que é o inferno e a salvação para que o povo pudesse ter o conhecimento e o entendimento. Assim, pode-se ter o conhecimento da definição dos pecados e os meios para se redimir dos mesmos. Dessa forma, Dante pretendia dar acesso à salvação ao povo que, até então, a igreja havia negado.

Ainda em relação à carta a Cangrande, Dante apresenta não apenas o dualismo da tragédia/comédia como modalidades literárias de seu percurso de condenação ou salvação individual, mas também o dualismo de natureza/pessoa. O poeta separa a culpa natural (pois todos nascem com o pecado original) da culpa pessoal. Sendo assim, faz um acordo cômico entre culpa pessoal e natural.

A contraposição entre o personagem "cômico" Dante, que se purifica da culpa pessoal mostrando até o fim a sua vergonha, e Édipo, o herói trágico que, enquanto pessoalmente inocente, não pode nem confessar a sua culpa nem aceitar a sua vergonha, não poderia ser mais clara. Assim, aquilo que era para os padres da Igreja o sinal da culpabilidade natural da criatura, da qual o herói trágico não podia sair, torna-se aqui, através da humilhação penitencial, o instrumento da reconciliação entre a culpa pessoal do homem e a sua inocência criatural. (AGAMBEN, 2014, p. 36)

De acordo com as reflexões de Agamben, disso tudo, pode-se pensar que a categorização do fim trágico ou cômico só pode se determinar em relação ao seu sujeito. O título Comédia carrega em si uma significação muito profunda e uma declaração de posição em relação a culpados ou inocentes perante a justiça divina. A tradução para o início trágico e o final bom é que o homem, com a sua origem culpada, atinge o final inocente de seus pecados. “O ‘poema sacro’ é uma justificação do culpado e não a culpabilidade do justo - é decididamente antitrágica" (AGAMBEN, 2014, p. 28-29).

O mais admirável no texto de Agamben é a possibilidade. Sim, a possibilidade de refletir uma vez mais com um enfoque inovador a respeito da Divina Comédia e as categorias italianas. Dentro do percurso reflexivo sobre os cantos dantescos, invariavelmente, nos deparamos com questões políticas que estruturam o quadro social do período temporal de composição dos mesmos. Com grande nível de riqueza compositiva, o florentino inseriu 
também uma ampla gama de informações sobre a filosofia aristotélica com cunho interpretativo oriundo do cristianismo.

Diante de tal particularidade percebida no texto de Dante, outra obra de Agamben, $O$ reino e a glória, pode servir como ferramenta de interpretação para a construção textual dantesco, pois o mesmo perfila a articulação entre o governo e o poder. Além disso, traz a reconstrução da história pelo paradigma teológico-econômico.

\section{Os fundamentos teológicos da política: uma investigação sobre a relação entre Oikonomia e Glória}

Giorgio Agamben, em $O$ reino e a glória, cria uma teologia política do poder político e busca mostrar ou desfazer uma contradição diante do fato dos regimes democráticos contemporâneos se guiarem, na prática da sua atuação política, por um paradigma que é identificado com formas totalitárias de governo. Deparando-se com tal contradição edificada, ficariam apenas duas saídas: a possibilidade de os regimes atuais não serem democráticos ou o conceito de que um estado de exceção como paradigma de governo seria um grande equívoco. Agamben, com um traçado engenhoso dos regimes políticos, chega à "conclusão" de que a maneira mais acertada de se enxergar o estado de exceção na modernidade não é através de lentes excepcionais, mas sim através da normalidade.

Agamben monta uma genealogia do estado de exceção para evidenciar que o mesmo teve o seu início com as primeiras ações revolucionárias do Estado Democrático, na época em que foi instituído, através de um decreto de 1791, que criou o estado de sítio. Este, por sua vez, seria, resumidamente: a cessação da lei com a finalidade de defender a própria lei, a suspensão provisória do regime democrático para a salvação da democracia, a isenção dos direitos individuais como uma maneira de garantir a cidadania e uma intervenção no mercado como garantia econômica à sua liberdade.

Agamben fornece exemplos de como o poder governamental manobrou medidas excepcionais afiguradas como técnicas normais de políticas. Segundo o filósofo, o estado de exceção surge expelido desse cenário de totalitarismo e se confunde com o estado de "guerra civil legal". Afirma ainda: Sob a pressão do paradigma do estado de exceção, é toda a vida política constitucional das sociedades ocidentais que, progressivamente, começa a assumir uma nova forma que, talvez, só hoje tenha atingido seu pleno desenvolvimento. (AGAMBEN, 2011, p. 27).

O estado de exceção está cada vez mais fundido e normatizado silenciosamente, sendo gradativamente mais aceito dentro de um cenário ao qual ele não se evidencia, porém, 
avança. Para Agamben, esse estado está travestido nas leis dentro do Direito e, dessa forma, caminha na democracia sem ser perturbado, “A declaração de um estado de exceção é progressivamente substituída por uma generalização sem precedentes do paradigma da segurança como técnica normal de governo" (AGAMBEN, 2011, p. 27-28).

É se mostrando comum e parte do direito da população que esse estado de exceção se incorpora como uma necessidade vital do estado e do povo. Uma democracia que deve ser protegida não se pode chamar de democracia, uma vez que o paradigma da ditadura constitucional trabalha, acima de tudo, como uma etapa que levará à inserção de um regime totalitário (AGAMBEN, 2011).

No capítulo intitulado "O poder e a glória”, Agamben aborda a questão da aclamação e do poder, os fatos históricos e articulações relacionadas ao poder e como o mesmo tornou-se oikonomia (economia). O filósofo busca analisar a articulação entre governo e poder, reconstruindo historicamente o paradigma teológico-econômico. Para tal, lança uma pergunta fundamental, que conduzirá a sua análise sobre a inteligibilidade e a opacidade no Reino e no Governo: "Inteligibilidade, porque a diferença entre Reino e Governo nunca se torna tão afetiva como na oposição assistentes/ministrantes; opacidade, porque o que pode ser uma política não do governo, mas da liturgia, não da ação, mas do hino, não do poder, mas da glória?" (AGAMBEN, 2011, p. 109).

Por que o poder e a glória necessitam um do outro nesse maquinário sociológico político? Agamben busca as respostas para essa pergunta levantando outras mais, não se limitando a esta obra, mas interligando-a a todas as suas outras pesquisas. Ele se utiliza de Michel Foucault para percorreros caminhos da política, uma vez que o mesmo tem uma vasta pesquisa voltada para tal abordagem.

Agamben levanta a questão da aclamação, definindo-a e chamando a atenção para a importância da mesma como centro dos dispositivos políticos. Uma delas, sobre os meios de comunicação nas democracias modernas, e como o governo utiliza-se das mesmas para o controle da massa. Além disso, os meios de comunicação jogam com a Glória, numa manipulação aclamativa e doxológica do poder que aparentemente havia desaparecido (AGAMBEN, 2011).

Agamben utilizou um ensaio sobre os anjos, de 1935, e uma dissertação, intitulada Heis Theos: Epigraphische, formgeschichtliche und religionsgeschichtliche Untersuchungen ["Um Deus: investigações sobre epigrafia, história da forma e história da religião"], do teólogo Erik Peterson, publicada em 1926, para levantar questões importantes sobre a 
aclamação, mesmo com duras críticas aos trabalhos do intelectual. O crítico consegue enxergar, nos estudos de Peterson, o não óbvio e levantar questões deturpadas pelo próprio pesquisador. É claro que muitas afirmações são acordadas, entre Agamben e Peterson, como a importância da aclamação.

Para compreender a importância das aclamações, como Peterson não deixa de observar, é essencial que "elas não eram de modo algum irrelevantes, e podiam, em determinadas circunstâncias, assumir um significado jurídico.” [...] É esse valor jurídico da aclamação que, em um ponto crucial, Peterson acolhe e enfatiza, enunciando, ao lado da tese da origem pagã de muitas aclamações cristãs, a de um nexo essencial que une direito e liturgia. (AGAMBEN, 2011, p. 188-189).

O crítico percorre diversos caminhos passando por definições e indagações sobre aclamações, liturgias, cerimônias e insígnias, para analisar todo o tema de poder e glória. Peterson não é o único ao qual Agamben recorre para elucidar o tema, pois acompanha as ideias dos mais diferentes pesquisadores, teóricos, teólogos, filósofos e até egiptólogos, como é o caso de Jan Assmann.

Uma das principais ponderações resultantes da investigação de Agamben, ao abordar a teologia política, mostrando elementos do passado que ainda atuam hoje, é que religião e política são, de certa forma, bilaterais e, apesar de distintas, são em determinados pontos semelhantes. Pois que a glória é justamente o ponto em que essa característica de duplicidade da relação entre política e teologia surge com mais clareza. E, dessa forma, Agamben (2011, p. 214) reflete:

\footnotetext{
Mais original - ou melhor, mais decisiva, do que a contraposição entre religião e política, entre poder espiritual e poder profano, é a glória em que coincidem. Aquilo que na perspectiva da teologia política schmittiana (ou da sua inversão em Assmann) aparecia como clara a distinção entre dois princípios, que encontram depois na secularização (ou na sacralização) seu ponto de contato, na perspectiva da glória - e da teologia econômica de que faz parte - ingressa em um limiar de indeterminação, em que nem sempre é fácil distinguir entre os dois elementos. Nesse sentido a teologia da glória constitui o ponto de contato secreto pelo qual teologia e política incessantemente se comunicam e trocam seus papéis entre si.
}

Ao ler os estudos supracitados de Agamben, podemos refletir sobre a realidade da dinâmica sociológica em que Dante estava inserido e, também, a relação da política e a teologia, a sacralização da política, a aclamação e as relações de poder que podem ser vistas na Divina Comédia. Com a sociedade do espetáculo, como também definiu Guy Debord, criou-se a necessidade de consentimento e aprovação. Para tal aprovação, precisa-se da aclamação, isto é, as mídias devem aclamar para poder glorificar o poder.

Agamben finaliza o capítulo afirmando que a sociedade pós-industrial é manipulada, apática e fragilizada. Ao se deixar controlar, a sociedade atual se caracteriza como uma 
máquina governamental. Para que tal situação seja modificada, a profanação deve ser imediata e, dessa forma, poderia se ter uma chance de criar uma nova política econômica. Cabe ao poeta identificar o dispositivo e profanar seu mecanismo para ajudar a alterar o rumo da história.

O estudo do filósofo abre uma reflexão sobre o papel do indivíduo na sociedade de hoje. Faz pensar sobre a apatia e a maquinação social diante de uma aclamação acirrada para com os meios. Como tal dispositivo foi imposto como "sagrado" e por que é alimentado tal fato? Tais questionamentos remetem às características da poética de Dante, pois é constante nas suas poesias a indagação sobre o poder governamental e a sociedade. Ao analisar tais pontos, que perpassam os tempos e sociedades, Agamben relaciona a importância da contemporaneidade com Dante e diz que o verdadeiro poeta é aquele que consegue olhar para o que não viveu, permanecendo no momento atual. $\mathrm{O}$ poeta contemporâneo é aquele que consegue fixar o seu olhar no presente e nele perceber o escuro, e não as luzes.

\section{Olhar o que não está ao alcance: o ser contemporâneo de si}

O que é o contemporâneo? Tal pergunta abre a aula inaugural do curso de Filosofia Teorética na Faculdade de Arte e Design de Veneza, em 2006-2007, ministrada por Giorgio Agamben. E é com esta mesma indagação que Agamben intitula um dos capítulos de $O$ que é o contemporâneo? e outros ensaios para instigar os leitores a refletirem sobre o que é ser contemporâneo.

A contemporaneidade pode ser percebida na produção literária dantesca e possibilita a sua aproximação com autores de diferentes tempos. Para percebermos a contemporaneidade em Dante, é importante compreendermos com maior largueza o que é ser contemporâneo. Para se aprofundar na referida questão, Agamben mais uma vez se utiliza de Foucault e da obra Considerações intempestivas.

\footnotetext{
Pertence verdadeiramente ao seu tempo, é verdadeiramente contemporâneo, aquele que não coincide perfeitamente com este, nem está adequado às suas pretensões e é, portanto, nesse sentido, inatual; mas exatamente por isso, através desse deslocamento e desse anacronismo, ele é capaz, mais do que os outros, de perceber e apreender o seu tempo. [...] A contemporaneidade, portanto, é uma singular relação com o próprio tempo, que adere a este e, ao mesmo tempo, dele toma distâncias. (AGAMBEN, 2009, p. 58-59)
}

O anacronismo, ou seja, o se desprender da linearidade cronológica, é o que torna o indivíduo um verdadeiro contemporâneo. Quem é capaz de se dissociar do tempo habitual e consegue perceber a importância dos tempos sem desvalorizar o seu próprio tempo presente. Agamben faz uma relação entre os seus estudos e fala do anacronismo também em Estâncias, 
quando diz:

Portanto, nesta perspectiva, precisamente é séria a relação com o passado que não o transforma simplesmente em necessidade, mas que sabe repetir (retomar, segundo a intenção kierkegaardiana) a sua possibilidade - inclusive e sobretudo a possibilidade de não ser (ou de ser de outra maneira), ou seja, a contingência. $O$ ato de criação não é, na realidade, segundo a instigante concepção corrente, um processo que caminha da potência para o ato para nele se esgotar, mas contém no seu centro um ato de descriação, no qual o que foi e o que não foi acabam restituídos à sua unidade originária na mente de Deus, e o que podia não ser e foi se dissipa no que podia ser e não foi. (AGAMBEN, 2012, p. 252)

A busca por outra realidade fora e dentro do seu tempo, como mencionado acima por Agamben, pode ser vista na poesia dantesca. O que Dante buscava na sua viagem surreal é o que a maioria dos indivíduos - confessos ou não - buscam: a salvação, a realização e a felicidade. Mesmo que a crença atual não seja a mesma da época de Dante, isto é, que nem todos vejam uma mimesis do inferno, purgatório e paraíso dantesco, com todos os seus personagens assustadores e angelicais, ainda assim, querem a verdadeira salvação, e é isso também que torna Dante um poeta tão contemporâneo. E, nesse lastro, com releituras e características semelhantes ou não, evidentes ou implícitas, encontramos diversos poetas que, ao se tornarem leitores de Dante, transpuseram para os seus versos a Divina Comédia.

São poucos os escritores que conseguem ser contemporâneos e Dante, com a Divina Comédia, é um desses. Como reflete o poeta e tradutor Octavio Paz (1993, p. 22): "Dante era finito e por isso pôde traçar a geografia do inferno, do purgatório e do paraíso. Mas esse mundo limitado era eterno: os homens estavam destinados a viver por séculos e, depois do Juízo Final, sem nenhuma mudança". O escuro são todos os tempos para quem experimenta a contemporaneidade. "Contemporâneo é, justamente, aquele que sabe ver essa obscuridade, que é capaz de escrever mergulhando a pena nas trevas do presente" (AGAMBEN, 2009, p. $63)$.

\section{Considerações finais}

Paz concorda com Agamben na questão da congruência dos tempos relacionada à poesia e diz: "A poesia que começa agora, sem começar, busca a intersecção dos tempos, o ponto de convergência. Diz que entre o passado esmaecido e o futuro desabitado, a poesia é o presente" (1993, p. 57). O presente se faz da presença que, por sua vez, é a união do passado, do presente e do futuro. Através da congruência dos tempos, anacrônico ou não, a poesia se realiza.

Escuridão e luz são muito citadas por Agamben para elucidar a ideia do olhar nesse 
contexto: "Todos os tempos são, para quem experimenta a contemporaneidade, obscuros" (2009, p.72). É contemporâneo quem sabe enxergar a escuridão e não apenas a luz. Através da escuridão do presente se pode verdadeiramente enxergar, pois se consegue amenizar a luz dos tempos.

\footnotetext{
Isso significa que o contemporâneo não é apenas aquele que, percebendo o escuro do presente, nele apreende a resoluta luz; é também aquele que, dividindo e interpolando o tempo, está à altura de transformá-lo e de colocá-lo em relação com os outros tempos, de nele ler de modo inédito a história, de "citá-la" segundo uma necessidade que não provém de maneira nenhuma do seu arbítrio, mas de uma exigência à qual ele não pode responder. (AGAMBEN, 2009, p. 72)
}

Dante, ao compreender muito bem o seu momento presente, conseguiu entender o passado e teorizar o futuro. Quebrou barreiras culturais, sociológicas e religiosas para defender a sua ideia e a sua crença. Buscou, através do novo, entender a história da sociedade e o futuro a que esta estava prometida, daí o termo a ele associado "poeta/profeta" e do qual ele também se apropria, pois, para ele, a Divina Comédia não era uma ficção, mas uma profecia e a verdade universal. Quanto a isso, em uma passagem do filósofo Jacques Derrida (2012, p. 78), em Pensar em não ver, lemos: “A memória, a antecipação, o futuro são modificações de um presente vivo que, quanto a ele, é originário". A necessidade de compreender a própria realidade, através da memória e da antecipação, e a sensação de deslocamento social estão presentes em Dante e atraem leitores para as suas obras, em especial da Divina Comédia, mesmo diante da imensidão do tempo e do espaço.

\section{Referências}

ALIGHIERI, Dante. Vida Nova. Tradução: Carlos Eduardo Soveral. Belo Horizonte: Lisboa Guimarães Editores, 1993.

AGAMBEN, Giorgio. Categorias italianas: estudos de poética e literatura. Tradução: Carlos Eduardo Schamidt Capela, Vinícius Nicastro Honesko; Tradução das passagens e citações em latim Fernando Coelho. Florianópolis: UFSC, 2014.

. Estâncias. Tradução de H. Burigo. Belo Horizonte: UFMG, 2012.

O que é o contemporâneo? e outros ensaios. Tradução de Vinícius Nicastro Honesko. Chapecó: Argos, 2009.

O reino e a glória: uma genealogia teológica da economia e do governo: homo sacer, II. Tradução de Selvino J. Assmann. São Paulo: Boitempo, 2011.

BERNARDINI, Aurora Fornoni. A coisa perdida - Agamben comenta Caproni. Organização e tradução Aurora Fornoni Bernardini. Florianópolis: UFSC, 2011.

DEBORD, Guy. A sociedade do espetáculo. Rio de Janeiro: Contraponto, 1997. 
DERRIDA, Jacques. Pensar em não ver: escritos sobre as artes do visível (1979-2004). Organização de Ginette Michaud, Joana Masó, Javier Bassas; tradução de Marcelo Jacques de Moraes. Florianópolis: UFSC, 2012.

PAZ, Octavio. A outra voz. Tradução de Wladir Dupont. São Paulo: Siciliano, 1993.

\section{The Divine Comedy Revisited: The Reflective Paths of Giorgio Agamben in Dantesque Verses}

Abstract: This essay intends to study some points of the Divine Comedy and its author, through the perspective of the Italian philosopher and literary critic Giorgio Agamben, and also, how he creates rhizomes among his texts using as object of study the Florentine poet. Being one of the most studied poems in different academic areas, the Dante an chants pass through time and remain updated and active not only in re-readings of poetic productions, but also in the eyes of scholars like Agamben. The literary critic presents a compilation of several texts, in a study differentiated from Dante's poetry with books like Estancias e Categorie Italiane. Agamben approaches the question of the meaning of poetry and how it can be decisive for poetic construction, as well as the conceptualization of enjambement; re-think about the title of Comedy; brings the understanding of the contemporaneity of the poets, especially Dante, and goes deeper into the theological foundations of politics to think about the question of acclamation as the center of political devices.

Keywords: Dante Alighieri. The divine Comedy. Giorgio Agamben. iterature. Politics.

Recebido em: 25/09/2017

Aceito em: 04/10/2017

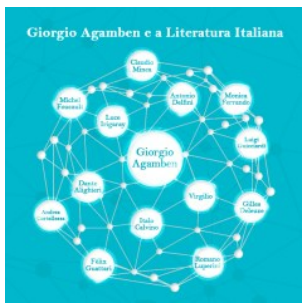

